\title{
"Reversed" intraguild predation: red fox cubs killed by pine marten
}

\author{
Marcin Brzeziński • Lukasz Rodak • Andrzej Zalewski
}

Received: 31 January 2014 / Accepted: 27 February 2014 / Published online: 27 March 2014

(C) Mammal Research Institute, Polish Academy of Sciences, Białowieża, Poland 2014

\begin{abstract}
Camera traps deployed at a badger Meles meles set in mixed pine forest in north-eastern Poland recorded interspecific killing of red fox Vulpes vulpes cubs by pine marten Martes martes. The vixen and her cubs settled in the set at the beginning of May 2013, and it was abandoned by the badgers shortly afterwards. Five fox cubs were recorded playing in front of the den each night. Ten days after the first recording of the foxes, a pine marten was filmed at the set; it arrived in the morning, made a reconnaissance and returned at night when the vixen was away from the set. The pine marten entered the den several times and killed at least two fox cubs. It was active at the set for about $2 \mathrm{~h}$. This observation proves that red foxes are not completely safe from predation by smaller carnivores, even those considered to be subordinate species in interspecific competition.
\end{abstract}

Keywords Martes martes $\cdot$ Vulpes vulpes $\cdot$ Interspecific killing $\cdot$ Competition $\cdot$ Carnivores

\section{Introduction}

Animal populations are limited by bottom-up and top-down processes (Terborgh and Estes 2010). Predator densities are affected mainly by food abundance (McLoughlin et al. 2000; Zalewski and Jędrzejewski 2006). However, in complex predator communities, the population dynamics of lower rank

Communicated by: Karol Zub

M. Brzeziński $(\bowtie) \cdot Ł$. Rodak

Faculty of Biology, University of Warsaw, Miecznikowa 1, 02-097 Warszawa, Poland

e-mail: marcinb@biol.uw.edu.pl

A. Zalewski

Mammal Research Institute, Polish Academy of Sciences,

Waszkiewicza 1, 17-230 Białowieża, Poland species (e.g. mesopredators) are also affected by interactions with high rank species (top predators). Top predators may limit mesopredator density by reducing access to food (exploitation competition) or by direct interactions (interference competition), of which interspecific killing (intraguild predation) is the most extreme (Sinclair et al. 2006). Intraguild predation is frequently observed interaction among predators (Polis et al. 1989; Arim and Marquet 2004), and highly asymmetric interspecific killing is usually mediated by a predator of larger body size that is able to kill smaller ones (Donadio and Buskirk 2006). Intraguild predation is common among medium-sized carnivores, e.g. red foxes Vulpes vulpes are known to kill Arctic foxes Alopex logopus or American martens Martes americana (Thompson 1994; Pamperin et al. 2006), and pine martens Martes martes prey on weasels Mustela nivalis and polecats Mustela putorius (Jędrzejewska and Jędrzejewski 1998). In some carnivore populations, mortality resulting from interspecific killing can be very high (review in Palomares and Caro 1999) and it may be considered a significant factor affecting small-sized predator populations (e.g. predation of red fox on stoat Mustela erminea; Mulder 1990). However, there have been few reports of killing of a large-sized predator by a smaller species (Hayward et al. 2007; Allen et al. 2012).

Two medium-sized predators, the pine marten and the red fox, co-occur over large parts of Europe where their geographic ranges overlap. Both species have similar food niches, with rodents, birds and carcasses predominating in their diets (Goszczyński 1986; Storch et al. 1990; Jędrzejewska and Jędrzejewski 1998; Zalewski 2007). As intraguild predation mainly occurs in predators with highly overlapping food niches (Donadio and Buskirk 2006), we might expect interspecific killing involving these two predator species. The red fox is a larger animal (up to $10 \mathrm{~kg}$ ) compared with the pine marten (up to $2 \mathrm{~kg}$ ), and therefore, studies focused on interspecific relations between these two species have always 
described the fox as the superior species. Marten remains have occasionally been found in the scats of red foxes (HartováNentvichová et al. 2010; Kidawa and Kowalczyk 2011), but this may have been the result of scavenging. Kurki et al. (1998) found no evidence that interspecific competition or intraguild predation by red fox affected the abundance of pine marten on a landscape scale. However, Lindström et al. (1995) revealed that pine martens suffer from intraguild predation by red foxes in Sweden and recorded several cases of casually observed predation by red foxes on martens. They estimated that the mortality of radio-collared pine martens in Scandinavia caused by red fox was as high as $50 \%$ (Lindström et al. 1995). Following an analysis of food habits and habitat selection of red foxes and pine martens, Storch et al. (1990) suggested that foxes negatively affect marten populations by direct predation rather than by interspecific competition for food resources. Available data on the population dynamics of both species in Scandinavia suggest a strong negative impact of the red fox on pine marten abundance. The drastic decrease in the red fox density in the 1980s correlated with a fivefold increase in pine marten density (Overskaug 2000). These findings suggest a highly asymmetric interaction between red fox and pine marten; therefore, we should expect that the latter species would display behaviour that reduces direct interactions with the former. In this report, we describe an unexpected and reversed interaction between pine marten and red fox.

\section{Methods}

In spring 2013, with the aim of recording badger Meles meles activity and behaviour, three camera traps (TV$6220 \mathrm{M})$ were deployed at a badger set in a managed mixed pine forest, about $1 \mathrm{~km}$ to the east of the boundary of Lake Łuknajno Biosphere Reserve $\left(53^{\circ} 49^{\prime} \mathrm{N}, 21^{\circ}\right.$ $38^{\prime} \mathrm{E}$ ), in north-eastern Poland. This badger set was located about $300 \mathrm{~m}$ from the forest edge, on the north-western slope of a hill overgrown mostly by pine Pinus silvestris, hornbeam Carpinus betulus and hazel Corylus avellana. Each camera trap was placed in front of a separate entrance (den), at a distance of about 3-4 m from the set. Badger tracks and soil removed from the set indicated that these three entrances were those most commonly used by the badgers. The camera traps were activated by animal movements, both during the day and night, and recorded 1-min long films with $10 \mathrm{~s}$ intervals. The monitoring of the badger set with camera traps lasted from the 24th of April until the 30th of June 2013, and in total, 316 films were recorded of three predator species (Fig. 1).

\section{Results and discussion}

From the 24th of April 2013 until the 9th of May (except four days), badgers were recorded entering and leaving the set (Fig. 1). On the 2nd of May, the first recording of an adult fox was made. Subsequently, the fox was filmed every second day, on the 4th, 6th and 8th of May, once together with a badger. On the 8th of May, at night, an adult fox (vixen) was filmed by the set with her cubs. After a short time, she left the scene and the young foxes were active alone in front of the set. On the next days (9th-11th of May), similar activity was recorded before dawn and after sunset (Fig. 1): the female played briefly with her cubs, but for most of the time, fox cubs were left alone. On the 12th of May, we did not record any activity of the vixen by the set and the cubs played by themselves close to the den (Fig. 2a). Maximum of five fox cubs were filmed in a one camera-trapping session, and therefore, we estimate that this was the size of the litter.

On the 12th of May at 06.26 in the morning, a pine marten was recorded approaching one of the set entrances (Fig. 2b). This individual was active at the set for about $8 \mathrm{~min}$. It walked around and sniffed the ground, and twice entered one of the dens, but did not disappear completely from the view of the camera trap (the tail was always visible). No other events were recorded at the set on this day until the evening activity of the fox cubs. The pine marten arrived again $23 \mathrm{~min}$ after the last recording of fox cubs (at 21.43.16). After $12 \mathrm{~s}$, it entered the den and re-emerged $13 \mathrm{~s}$ later. It entered the den once again for about $10 \mathrm{~s}$, came out, and then it stayed in the den entrance and looked around for $8 \mathrm{~s}$ (Fig. 2c). During the next minute, it entered the den and came out two more times. From 21.45.02 to 21.45 .15 , the pine marten circled the entrance, sniffing and looking around, before rapidly entering the den. It was underground for $19 \mathrm{~s}$ and then leaped out of the den holding a fox cub, which was still alive. The kill took place in front of the den and lasted about $6 \mathrm{~s}$. After killing the cub, the pine marten with its prey disappeared from the view of the camera trap (21.45.40). At 21.49.44, it returned and rapidly entered the same den. After $58 \mathrm{~s}$, it emerged with another fox cub and quickly withdrew into the forest. This time, we could not determine whether the fox cub was still alive or if it had already been killed underground. Four minutes later, at 21.54.06, the pine marten returned to the set once again and for about $2 \mathrm{~min}$, it penetrated another den, entering and coming out of the entrance three times. Subsequent recordings of the pine marten at the set were made from 22.19 until 00.02. During these visits, the pine marten entered the den three more times, but no other successful fox cub kills were recorded. On this night, the total period of pine marten activity (including intervals) near the set was $2 \mathrm{~h}$ and $19 \mathrm{~min}$.

After the withdrawal of the pine marten, there were no further recordings at the set until 20.23 on the 13th of May (Fig. 1), when the vixen was filmed emerging from one of the 


\begin{tabular}{|c|c|c|c|c|c|c|c|c|c|c|c|}
\hline Date & Time & Badger & Vixen & Fox cubs & Marten & Date & Time & Badger & Vixen & Fox cubs & Marten \\
\hline \multirow{2}{*}{ 24-Apr } & 19:00-20:00 & 3 & & & & \multirow{4}{*}{ 10-May } & 03:00-04:00 & & & 10 & \\
\hline & $20: 00-21: 00$ & 4 & & & & & 04:00-05:00 & & & 4 & \\
\hline \multirow{2}{*}{ 25-Apr } & 00:00-01:00 & 1 & & & & & $22: 00-23: 00$ & & 1 & 9 & \\
\hline & 01:00-02:00 & 1 & & & & & $23: 00-00: 00$ & & & 7 & \\
\hline \multirow{3}{*}{ 26-Apr } & 20:00-21:00 & 3 & & & & \multirow{5}{*}{ 11-May } & 00:00-01:00 & & 1 & 8 & \\
\hline & $21: 00-22: 00$ & 2 & & & & & 01:00-02:00 & & & 1 & \\
\hline & $22: 00-23: 00$ & 4 & & & & & 03:00-04:00 & & & 12 & \\
\hline \multirow{2}{*}{ 27-Apr } & 20:00-21:00 & 4 & & & & & 22:00-23:00 & & & 4 & \\
\hline & $21: 00-22: 00$ & 1 & & & & & $23: 00-00: 00$ & & & 9 & \\
\hline \multirow{5}{*}{ 28-Apr } & 00:00-01:00 & 1 & & & & \multirow{9}{*}{ 12-May } & 01:00-02:00 & & & 1 & \\
\hline & 04:00-05:00 & 3 & & & & & 02:00-03:00 & & & 31 & \\
\hline & 19:00-20:00 & 7 & & & & & 03:00-04:00 & & & 12 & \\
\hline & $20: 00-21: 00$ & 1 & & & & & 04:00-05:00 & & & 3 & \\
\hline & 21:00-22:00 & 3 & & & & & $06: 00-07: 00$ & & & & 4 \\
\hline \multirow{2}{*}{ 29-Apr } & $21: 00-22: 00$ & 4 & & & & & $20: 00-21: 00$ & & & 2 & \\
\hline & $22: 00-23: 00$ & 1 & & & & & $21: 00-22: 00$ & & & 8 & 6 \\
\hline \multirow{2}{*}{ 30-Apr } & 22:00-23:00 & 1 & & & & & $22: 00-23: 00$ & & & & 5 \\
\hline & 23:00-00:00 & 1 & & & & & 23:00-00:00 & & & & 1 \\
\hline \multirow{5}{*}{ 1-May } & 00:00-01:00 & 3 & & & & \multirow{4}{*}{ 13-May } & 00:00-01:00 & & & & 1 \\
\hline & 18:00-19:00 & 2 & & & & & $20: 00-21: 00$ & & 6 & & \\
\hline & 19:00-20:00 & 4 & & & & & $21: 00-22: 00$ & & 6 & & \\
\hline & $21: 00-22: 00$ & 1 & & & & & $23: 00-00: 00$ & & 1 & & \\
\hline & $22: 00-23: 00$ & 2 & & & & \multirow{4}{*}{ 14-May } & $00: 00-01: 00$ & & 1 & & \\
\hline 2-May & 03:00-04:00 & & 2 & & & & 03:00-04:00 & & 1 & & \\
\hline \multirow{3}{*}{ 3-May } & 00:00-01:00 & 1 & & & & & 21:00-22:00 & & 1 & & \\
\hline & 04:00-05:00 & 1 & & & & & $22: 00-23: 00$ & & 2 & & \\
\hline & 19:00-20:00 & 2 & & & & \multirow{2}{*}{ 15-May } & 00:00-01:00 & & 1 & & \\
\hline \multirow{3}{*}{ 4-May } & 01:00-02:00 & 1 & & & & & 06:00-07:00 & & & & 2 \\
\hline & $19: 00-20: 00$ & 4 & & & & \multirow{2}{*}{ 16-May } & 18:00-19:00 & 1 & & & \\
\hline & $20: 00-21: 00$ & 7 & 2 & & & & 19:00-20:00 & 1 & & & \\
\hline \multirow{3}{*}{ 6-May } & 04:00-05:00 & 1 & 2 & & & 25-May & 01:00-02:00 & 1 & & & \\
\hline & 19:00-20:00 & 1 & & & & 26-May & $22: 00-23: 00$ & 1 & & & \\
\hline & 23:00-00:00 & & 1 & & & \multirow{2}{*}{ 27-May } & 18:00-19:00 & 1 & & & \\
\hline 8-Маv & 04:00-05:00 & & 1 & & & & 22:00-23:00 & 1 & & & \\
\hline o-ividy & $23: 00-00: 00$ & & 1 & 4 & & 28-May & 01:00-02:00 & 2 & & & \\
\hline & 03:00-04:00 & & 2 & 4 & & 4-Jun & 21:00-22:00 & 1 & & & \\
\hline Q-Mav & 04:00-05:00 & 1 & & 1 & & 5 - lun & 08:00-09:00 & 2 & & & \\
\hline S-ividy & $22: 00-23: 00$ & & 1 & 15 & & s-san! & 18:00-19:00 & 3 & & & \\
\hline & 23:00-00:00 & & & 8 & & 8 -lun & 03:00-04:00 & 6 & & & \\
\hline & & & & & & o-vun & $20: 00-21: 00$ & 7 & & & \\
\hline & & & & & & 10 - & 03:00-04:00 & 2 & & & \\
\hline & & Daylight & & & & 10-Jun & 19:00-20:00 & 1 & & & \\
\hline & & Dawn o & usk & & & 11-Jun & 10:00-11:00 & 1 & & & \\
\hline & & Night & & & & T1-Jun & 18:00-19:00 & 1 & & & \\
\hline & & & & & & 16-Jun & 00:00-01:00 & 2 & & & \\
\hline & & & & & & (10-5um & $01: 00-02: 00$ & 1 & & & \\
\hline & & & & & & Total numb & r of films & 111 & 33 & 153 & 19 \\
\hline
\end{tabular}

Fig. 1 Timeline of events at the badger set from 24th of April until 16th of June 2013. Numbers in cells indicate number of films with predators recorded during 1-h interval

dens (her return was not recorded). With some intervals, she was active around the set for the whole night, during which time she was recorded entering and coming out of the dens and intensely sniffing the ground near the den entrances (Fig. 2d). The last recordings of this fox were made on the following night when she visited the set three times between
21.44 and 00.04 , at intervals of about $1 \mathrm{~h}$. After that vixen was not observed at the set, but interestingly, on the 15th of May in the morning, a pine marten was recorded as it sniffed around one of the entrances. One day later, on the 16th of May, a badger was recorded near the set. Over the next 8 days, no badgers were filmed there. They were recorded occasionally 
Fig. 2 a Fox cubs playing around the entrance to the den. $\mathbf{b}$ Pine marten making a reconnaissance at the badger set. $\mathbf{c}$ Pine marten at the entrance to the den prior to the attack. d Vixen looking for her cubs the day after the pine marten attack
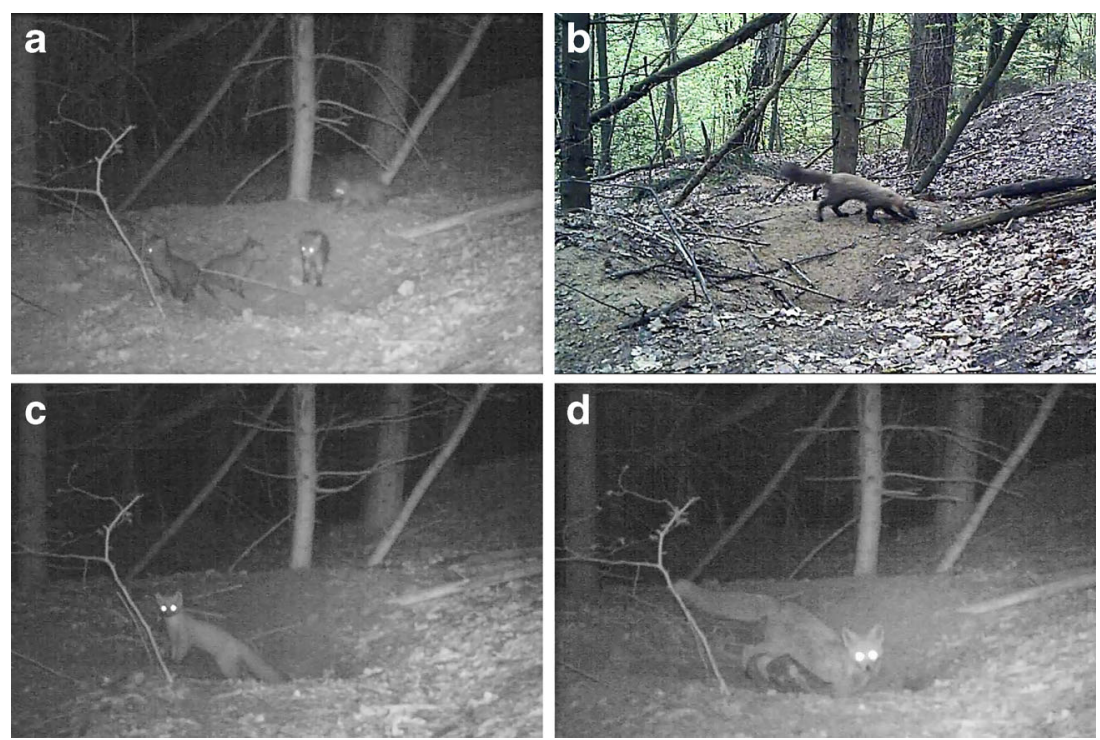

from 25th of May until 16th of June. Camera trap monitoring of the set continued until the end of June, but no further recordings were made of any of the predators.

On the films, it was not possible to recognize if the pine marten that killed the foxes was the same as observed earlier near the set, but high intersexual territorial behaviour of this species (Zalewski and Jeedrzejewski 2006) and similar size of the recorded animal may indicate that it was the same specimen. The reconnaissance by the pine marten at the set about $15 \mathrm{~h}$ prior to the hunt suggests that this individual had deliberately entered the fox den and killed the cubs after recognizing the presence of potential prey and estimating the risk of being detected by an adult fox female. The night attack was also preceded by watchful behaviour: the pine marten sniffed around before entering the den and once it had done so, reemerged several times to look around. The successful capture was not made immediately; the pine marten entered the den at least four times prior to it. It is hard to say whether these were unsuccessful attacks or if the pine marten could not find the cubs underground. Unfortunately, we did not record all of the important events leading up to the predation act. It would be interesting to know whether the pine marten observed the den prior to the attack and, if so, for how long. It seems likely that the vixen was not present in the den at the time of the attack, but our camera traps did not record the moment when she abandoned her cubs. It is also not clear what happened to the rest of the fox cubs. They might have all been killed by the pine marten (which entered the den at least six more times after the second recorded kill) but were not taken away from the den (surplus killing); they were killed and taken away through one of the old exits that was not monitored by camera traps or they escaped through these exits.

In carnivores, interspecific killings are mostly "one way", with a larger species preying upon a smaller one. According to data collected by Palomares and Caro (1999), carnivores smaller than $10 \mathrm{~kg}$ comprise only $18.5 \%$ of killer species, but they predominate among prey species $(57.4 \%)$. For example, the number of mustelid species (which are mostly small- or medium-sized carnivores) killed by other predators is much greater than the number of mustelids recorded as killer species. Also, the number of different pairwise interactions recorded is much larger when a mustelid species is the prey and not the killer (Palomares and Caro 1999). Donadio and Buskirk (2006) concluded that although resource exploitation, predatory habits and taxonomy are influential in predisposing carnivores to kill each other, the relative difference in body size of the killer and the prey is especially important.

In intraguild predation, there are two possibilities for the killing of a larger carnivore species by a smaller one. The first is the killing of a larger adult individual by predators that hunt in groups, and the second is the killing of a cub or juvenile individual that is small enough to be captured, handled and killed, even by a solitary hunting carnivore (Palomares and Caro 1999). However, the second possibility is still rather a case of a large predator killing a smaller one, despite the fact that adults of a prey species are larger than a killer species. Therefore, in such a case, the size asymmetry between prey and predator does fall within what is expected. The pine marten, which is a solitary hunter, is able to kill fox cubs, as their size does not exceed the body mass of the marten (about $1.5 \mathrm{~kg}$ ) until they are 8-10 weeks old (Fairley 1970; Goszczyński 1995). Inexperienced fox cubs, which are often left in the den by hunting vixens, start to come out and explore their surroundings at about the age of 6 weeks (Goszczyński 1995), and they are particularly vulnerable to predator attacks at this time. The close vicinity of the den, where they can escape when endangered, helps to reduce predation by raptors, but the den is not good protection against the pine marten. As 
recorded by our camera traps, a pine marten easily entered and penetrated a badger set to secure multiple kills. Obviously, such an act of predation is possible only against cubs that are not guarded by an adult and are defenceless in the face of a carnivore such as the pine marten. Despite the high predation risk from the adult fox, the pine marten spent a relatively long time near the den. Unfortunately, we could not observe the behaviour of the pine marten outside of the view of the cameras, so it is difficult to state if it avoided the area of the set most of the time and only came in when it felt the risk was sufficient low. The absence of the vixen was for sure an opportunity provided by chance, so after the pine marten explored the set and noticed signs of unattended cubs, it attacked them and killed with a high level of determination. The observed behaviour of the pine marten indicates that this type of attack may occur more often than thought.

Ecological and behavioural factors affecting intraguild predation are poorly understood (Palomares and Caro 1999). Killed predator may be an additional source of food, especially in time when other food sources are scarce. However, competition for food between predators has been suggested as a key factor precipitating interspecific killing (Polis et al. 1989; Palomares and Caro 1999). Pressure to reduce abundance of competitors may be directed to adult but also to juvenile animals. Taking into consideration that in spring, the food availability is high for pine marten and risk of mortality during exploration of fox den is significant, we speculate that such behaviour is directed to reduce potential competitor rather than to obtain food. Mortality rates of fox cubs are hard to estimate, and the causes of their death are usually unknown. Our accidental recording of pine marten predation on fox cubs implies that smaller predators, particularly when their density is very high, may reduce the reproduction success and affect the population density of a larger predator.

Acknowledgments We are grateful to John Gittins for the English language editing.

\section{References}

Allen BL, Fleming PJS, Hayward M, Allen LR, Engeman RM, Ballard G, Leung LK-P (2012) Top-predators as biodiversity regulators: contemporary issues affecting knowledge and management of dingoes in Australia. In: Lameed GA (ed) Biodiversity enrichment in a diverse world. InTech Publishing, Rijeka, pp 85-132

Arim M, Marquet PA (2004) Intraguild predation: a widespread interaction related to species biology. Ecol Lett 7:557-564
Donadio E, Buskirk SW (2006) Diet, morphology and interspecific killing in carnivora. Am Nat 167:524-536

Fairley JS (1970) The food, reproduction, form, growth and development of the fox Vulpes vulpes (L.) in north-east Ireland. Proc R Ir Acad 69: $103-137$

Goszczyński J (1986) Diet of foxes and martens in central Poland. Acta Theriol 31:491-506

Goszczyński J (1995) Red fox. A monograph. Oikos, Warszawa [In Polish]

Hartová-Nentvichová M, Šálek M, Červený J, Koubek P (2010) Variation in the diet of the red fox (Vulpes vulpes) in mountain habitats: effects of altitude and season. Mamm Biol 75:334-340

Hayward MW, Kerley GIH, Adendorff J, Moolman LC, O'Brien J, Sholto-Douglas A, Bissett C, Bean P, Fogarty A, Howarth D, Slater R (2007) The reintroduction of large carnivores to the Eastern Cape Province, South Africa: an assessment. Oryx 41: 205-214

Jędrzejewska B, Jędrzejewski W (1998) Predation in vertebrate communities. The Białowieża Primeval Forest as a case study. Springer, Berlin

Kidawa D, Kowalczyk R (2011) The effects of sex, age, season and habitat on diet of the red fox Vulpes vulpes in northeastern Poland. Acta Theriol 56:209-218

Kurki S, Nikula A, Helle P, Lindén H (1998) Abundances of red fox and pine marten in relation to the composition of boreal forest landscapes. J Anim Ecol 67:874-886

Lindström ER, Brainerd SM, Helldin JO, Overskaug K (1995) Pine marten - red fox interactions: a case of intraguild predation? Ann Zool Fenn 32:123-130

McLoughlin PD, Ferguson SH, Messier F (2000) Intraspecific variation in home range overlap with habitat quality: a comparison among brown bear populations. Evol Ecol 14:39-60

Mulder JL (1990) The stoat Mustela erminea in the Dutch dune region, its local extinction, and possible cause: the arrival of the fox Vulpes vulpes. Lutra 33:1-21

Overskaug K (2000) Pine marten Martes martes versus red fox Vulpes ulpes in Norway; an inter-specific relationship? Lutra 43:215-221

Palomares F, Caro TM (1999) Interspecific killing among mammalian carnivores. Am Nat 153:492-508

Pamperin NJ, Follmann EH, Petersen B (2006) Interspecific killing of an Arctic fox by a red fox at Prudhoe Bay, Alaska. Arctic 59:361-364

Polis GA, Myers CA, Holt RD (1989) The ecology and evolution of intraguild predation: potential competitors that eat each other. Annu Rev Ecol Syst 20:297-330

Sinclair ARE, Fryxell JM, Caughley G (2006) Wildlife ecology, conservation, and management. Blackwell

Storch I, Lindström E, de Jounge J (1990) Habitat selection and food habits of the pine marten in relation to competition with the red fox. Acta Theriol 35:311-320

Terborgh J, Estes JA (2010) Trophic cascades: predators, prey and the changing dynamics of nature. Island Press, Washington

Thompson ID (1994) Marten population in uncut and logged boreal forest in Ontario. J Wildl Manag 58:272-280

Zalewski A (2007) Does size dimorphism reduce competition between sexes? The diet of male and female pine martens at local and wider geographical scales. Acta Theriol 52:237-250

Zalewski A, Jędrzejewski W (2006) Spatial organisation and dynamics of the pine marten Martes martes population in Białowieża Forest (E Poland) compared with other European woodlands. Ecography 29:31-43 